\title{
NONLINEAR FE MODELLING OF ANCHORAGE BOND IN REINFORCED CONCRETE
}

\author{
Appa Rao G', Kadhiravan. $D^{2}$ \\ ${ }^{1}$ Associate Professor, ${ }^{2}$ Research Student, Dept. of Civil Engg, IITM, Chennai 600036, India, garao@iitm.ac.in
}

\begin{abstract}
The transfer of forces from the surrounding concrete to the reinforcing bars in reinforced concrete $(R C)$ can be influenced by several parameters. In this paper an attempt has been made to study the influence of specimen geometry, bar diameter, strength of concrete, lateral confinement and embedment length on the bond properties of concrete. The embedment length of the bar was varied between $50 \mathrm{~mm}$ and $400 \mathrm{~mm}$ by varying the diameter of the bar, strength of concrete and lateral confinement. The different bar diameters of 16, 20 and $25 \mathrm{~mm}$ were selected along with three different concrete strengths of 25, 40 and 65MPa. The specimens with the above parameters were modeled by using a nonlinear finite element analysis package. It has been found that for the same geometry, the specimens with small bond length exhibited high bond strength. With the range of bar diameters considered the bond strength of concrete decreases as the diameter of the bar increases. The splitting failure has been observed in unconfined concrete, while the pullout failure was predominant when the concrete laterally confined. In case of large embedment length, the post peak plateau is prolonged with small diameter bars when compared to the large diameter bars. The descending branch of the bond stress-slip response with large diameter bars has been found to be steep.
\end{abstract}

Keywords: Bond Stress, FE Analysis, Embedment Length, Confinement, Bar Diameter, Pull-out Specimens.

\section{INTRODUCTION}

The interaction of the surrounding concrete with the reinforcing steel strongly influences the behavior of reinforced concrete members. The bond stress-slip response is influenced by several factors such as reinforcing bar, concrete strength and state of stress in the reinforcing bar and the surrounding concrete, type of bar, relative rib area, bar diameter, length of embedment, lateral confinement, type of loading, clear cover, clear spacing between bars, number of layers of bars, casting direction and bar position. Rehm [1] studied on the relative rib area for comparison of bond characteristics of different bars. High ribs increase bond strength because high interaction stress increases the probability of longitudinal cracking. Tefers and Olsson [2] observed that increasing the rib height improves the bond strengt. The bond slip at the maximum load decreases as the relative rib area increases. If the rib spacing is too short then the bar acts as a plain bar. Mathey and Watsein [3] investigated the bond in beam and pull-out specimens with high strength deformed bars. It has been reported that the bond strength decreases as the embedment depth increases for a given bar diameter. Further, the bond strength decreases with increase in the bar diameter. Hansen and Liepins [4] reported an increase in the bond strength under dynamic loading in relation with the static loading, which is due to the increase in the strength of steel under the dynamic loading. Further, the progressive bond failure and large slip were expected from the large repeated loading. Goto [5] investigated the crack pattern using injecting ink around the deformed bars. From the dye pattern test, the lateral and longitudinal cracking in concrete around the reinforcing bar have been studied. Soroushian and Choi [6] reported that the bond strength decreases as the bar diameter increases. Also a slight increase in the pre-peak local bond tangent stiffness was observed. The post-peak bond strength and the characteristic bond-slip values are not influenced by the bar diameter.

Harajli et al. [7] reported on the effect of confinement on bond strength between steel bars and concrete. The concrete confined with ordinary steel reinforcement has been found to improve the bond strength but the ductility was significantly improved in the post-peak region. The bond strength increases in proportion with the modulus of elasticity of the confining steel, which is independent of the yield strength. Lutz and Gergely [8] studied the bond behavior, the associated slip and cracking for the reinforcing bars with different surface characteristics. Jiang et al. [9] developed new test method by cutting the reinforcing bars into two halves and placing in two opposite sides of the cross section to study the local slip, secondary cracking and strain distribution in the concrete surrounding the interface. Comparison of test results with the conventional approaches revealed that many of the aspects of the bond transfer mechanism are identical. A simple onedimensional analysis has been carried out to predict the stresses in the steel and the surrounding concrete, local bondslip response, tension stiffening and total elongation of the reinforcing bar. 
Soroushian et al. [10] studied the influence of strength of concrete with different lateral confinements. The confinement of concrete by the transverse reinforcement seems to be influenced by the local bond behavior of deformed bars directly. Somyaji et al. [11] and Jiang et al. [9] performed several experimental and theoretical investigations on the bond response with normal strength concrete. De Larrard et al. [12] investigated the influence of bar diameter on the bond strength in high performance concrete. The bond strength increases with increasing the tensile strength of concrete, which varies at a higher rate using smaller bar diameter. Darwin et al. [13] studied the development length criteria with the conventional and with high relative rib area. On the basis of a statistically developed expression, the development length and the splice strength of the reinforcement for concrete with compressive strength varying between 17 and $110 \mathrm{MPa}$, with and without lateral confinement reinforcement, was investigated. The effects of the cover, bar spacing, development/spliced reinforcement were incorporated in the design equation. Eligehausen et al. [14] reported comprehensive studies on the influence of the bar diameter embedded in normal strength concrete. It has been observed that the maximum bond capacity decreased slightly with increasing the bar diameter. The frictional bond strength was not influenced by the bar diameter, lug spacing or the relative rib area. CEB Task Group [15] presented a general description of the local bond law for the tensile forces.

\section{STANDARD BOND TESTS}

All the test methods can be classified in to two categories according to their form, namely transfer type, and anchorage or development type. Pull-out and beam-end forms of test lies in the anchorage type and clearly expresses the idea of anchoring a bar. One end of the bar is in tension and the other end is unstressed and the equilibrate reaction is supplied through surrounding concrete. In the transfer test, both the ends of the bar are stressed in tension and force is not applied directly to the concrete.

\subsection{Pull-Out Specimens}

The Indian Standard IS 2770 [16] specified pull-out test on a single reinforcing bar embedded in a cube of size 150x150x150 mm (for bar size ranging between 12-25mm) with adequate projected length of bar as shown in Fig. 1. The embedment length is provided over the entire length of the cube of size $150 \mathrm{~mm}$. The lateral confinement is provided around the embedded bar by steel spirals of $6 \mathrm{~mm}$ diameter at $25 \mathrm{~mm}$ pitch, where the applied load and the corresponding slip are monitored with the loading machine and LVDTs respectively. The average bond stress is calculated by dividing the applied load by the embedded area of the bar.

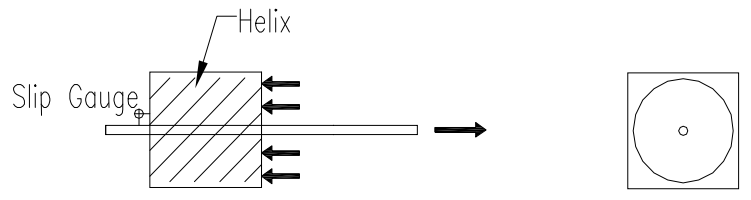

Fig1. Pull-out Specimen as per IS 2770 [16].

RILEM Standard [17] employs a bond length of 5 times the bar diameter in a concrete cube measuring 10 bar diameters. A plastic sleeve covers the bar over the half of the concrete length to minimize the platen restraint effect at the loaded end. The tension force ' $F$ ' applied can be transformed by the following formula in to bond stress, $\tau_{\mathrm{dm}}$ and converted linearly to the medium concrete strength, $\mathrm{f}_{\mathrm{cm}}$

$$
\tau_{\mathrm{dm}}=\frac{\mathrm{F}}{5 \pi \mathrm{d}_{\mathrm{s}}^{2}}\left(\frac{\mathrm{f}_{\mathrm{cm}}}{\mathrm{f}_{\mathrm{c}}}\right)
$$

Where

$\mathrm{F}=$ applied tensile force

$\mathrm{f}_{\mathrm{cm}}=30$ or $25.5 \mathrm{~N} / \mathrm{mm}^{2}$ for cube and cylinder test specimens respectively

$\mathrm{f}_{\mathrm{m}}=$ average from the tested specimens

$\mathrm{d}_{\mathrm{s}}=$ bar diameter

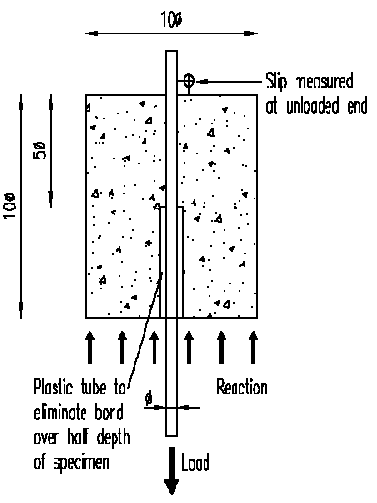

Fig2. RILEM Pull-out Specimen.

The RILEM Beam Specimen RC5 [18] as shown in Fig. 3 consists of two parallelepiped RC prisms $(600 \mathrm{~mm} \times 240 \mathrm{~mm} \times$ $150 \mathrm{~mm}$ ) is interconnected at the bottom by the reinforcing bar and at the top kept intact by means of a hinge. The specimen is loaded in flexure under four-point loading. The slip is measured between the two prisms and also at the end of the bar. Beam specimens are much more costly than the pull-out specimens. Casting of the specimen involves cost and it is also difficult to fabricate due to complicated reinforcing bar details. 


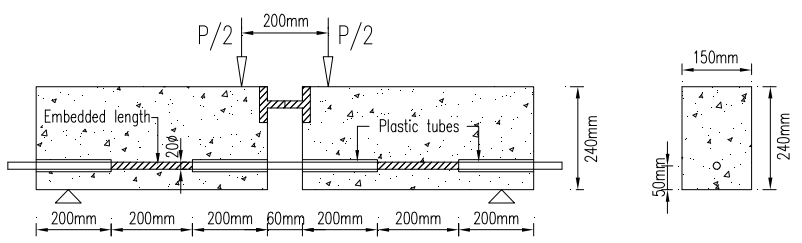

Fig3. RILEM Beam Details.

\section{PROVISIONS ON DEVELOPMENT LENGTH}

For design of reinforced concrete structures for bond, several codes of practice recommended expressions for estimating the development length as a function of mean bond stress. The design equations estimate the development length necessary to achieve the yield strength of the steel reinforcement under loading. The minimum embedded length required to develop the yield strength of the steel reinforcement bar is called the development length. The bond stress is an important factor for the development of stresses in the bars. The development length provisions by various codes of practice such as IS, ACI, $\mathrm{BS}$, and Euro code are discussed in the following sections.

\subsection{Indian Standard}

IS 456 [19], the code of practice for the design of plain and reinforced concrete considers the basic development length as a function of yield strength of reinforcement, diameter of bar and the design bond strength, which is a function of the compressive strength of concrete is given below

$$
L_{d}=\frac{\phi \sigma_{s}}{4 \tau_{b d}}
$$

Where $\sigma_{s} \quad=0.87 f_{y}$

$\Phi \quad$ = bar diameter

$\tau_{b d} \quad=$ design bond strength

\subsection{American Standard}

The American code, ACI 318 [20] specified the development length expression based on a non-linear regression analysis of the data base on bond strength. The ACI building code [20] stipulates an upper limit of concrete compressive strength of $69 \mathrm{MPa}$. The reason for this upper limit is due to lack of authentic test data on HSC. Subsequent revisions were made to incorporate the other parameters in the development length expression at a critical section by the following formula,

$$
l_{d}=\frac{9}{10} \frac{f_{y}}{\sqrt{f_{c}^{\prime}}} \frac{\psi_{t} \psi_{e} \psi_{s} \lambda}{\left(\frac{c_{b}+K_{t r}}{d_{b}}\right)} d_{b}
$$

Where $\psi_{\mathrm{t}}=$ reinforcement location factor

$\psi_{\mathrm{e}}=$ coating factor

$\psi_{\mathrm{s}}=$ reinforcement size factor

$\lambda=$ light weight aggregate factor

$c_{b}=$ spacing or cover dimension, $\mathrm{mm}$

$\mathrm{K}_{\mathrm{tr}}=$ transverse reinforcement index,

$$
K_{t r}=\frac{A_{t r} f_{y t}}{10 *{ }^{*} n}
$$

\subsection{ACI Committee 408}

The ACI committee 408 [21] recommends the ratio of development length of high relative rib area reinforcing bars in tension, $l_{\mathrm{d}}$.to- the bar diameter, $d_{\mathrm{b}}$ as

$$
\frac{l_{d}}{d_{b}}=\frac{\left(f_{y} / f_{c}^{1 / 4}-1900 \omega\right) \alpha \beta \lambda}{72\left(\frac{c \omega+K_{t r}}{d_{b}}\right)}
$$

Where $f_{y}=$ yield strength of reinforcement

$f_{c}^{\prime 1 / 4}=$ fourth root of compressive strength of concrete

$\alpha \quad=$ reinforcement location factor

$\beta=$ coating factor

$\lambda=$ light weight aggregate factor

$\omega=0.1 \frac{C_{\max }}{C_{\min }}+0.9 \leq 1.25$, factor reflecting large cover or spacing

$K_{t r}=C_{R}\left(0.72 d_{b}+0.28\right) \frac{A_{r r}}{s n}$, transverse reinforcement index

$C_{R}=44+330\left(R_{r}-0.10\right)$, relative rib area factor

\subsection{European Standard (EN 2)}

The Euro Code, EN-2 [22] specified a simple expression for estimating the basic anchorage length, $l_{b}$ of reinforcing bars in concrete

$$
l_{b}=\frac{\phi \sigma_{s d}}{4 f_{b d}}
$$

$$
\text { Where } \begin{aligned}
\sigma_{\mathrm{sd}} & =\text { design stress of bar } \\
\Phi & =\text { bar diameter } \\
f_{\mathrm{bd}} & =\text { design bond strength }
\end{aligned}
$$

\subsection{British Standard}

The British code [23] provides the expression for estimating the development length, which is very similar to that of IS 456 and EN-2. The development length $L_{d}$ is given by

$$
L_{d}=\frac{f_{y d} \varphi}{4 f_{b u}}
$$

Where $f_{\text {sd }} \quad=$ design stress of bar 


$$
\begin{aligned}
\Phi & =\text { bar diameter } \\
f_{\mathrm{bu}} & =\text { design bond strength, } f_{b u}=\beta \sqrt{f_{c u}} \\
f_{\mathrm{cu}} & =\text { concrete cube strength }
\end{aligned}
$$

The development length requirements specified by the various codes indicate the bond strength of concrete as a variable in terms of several parameters. However, the provisions by the codes are based on the test results from normal strength concrete (NSC). In case of the bundled bars, in some codes, the development length of the individual bars is increased due to the reduction of the anchorage bond strength caused by the reduced interface between the steel reinforcement and the surrounding concrete. The concept of the equivalent diameter of the bundled bars is also considered in some other codes.

\section{MODELLING OF BOND IN CONCRETE}

Two different elements have been proposed in the finite element analysis of the reinforced concrete structures to date by various researchers for taking the bond-slip response in to account. They are; bond link element and bond zone element.

\subsection{Bond Link Element}

Bond link element as shown in Fig. 4 consists of two orthogonal springs which will connect and transfer the shear and the normal forces between the reinforcing bar node and the adjacent concrete node. Since the link element doesn't have any physical dimensions, the two connected nodes originally occupy the same location in the finite element mesh of the undeformed structure.

\subsection{Bond Zone Element}

The bond zone element is shown Fig. 5, is significantly different from the bond link element. The most important difference is the finite dimension. In the bond zone element, the contact surface between the reinforcing bar and the concrete in the immediate vicinity of the reinforcing bar are modeled by a material law, which represents the special properties of the bond zone. In this model the bond stress is the sum of the resistance against slip and the mechanical interlocking.

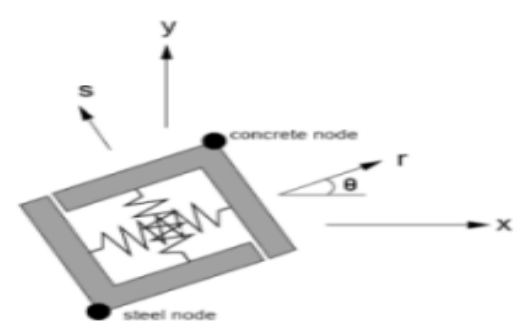

Fig4. Bond Link Element

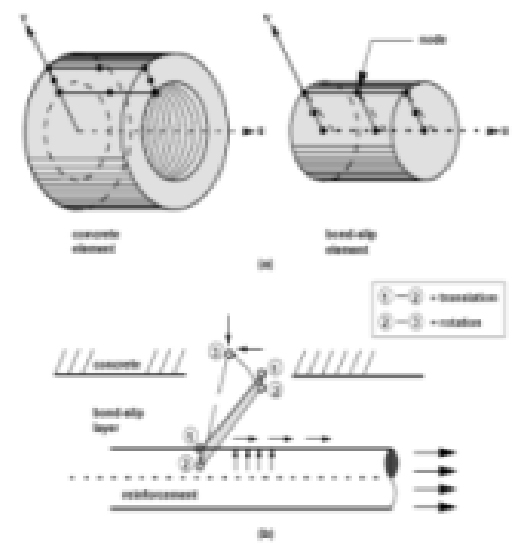

Fig5. Bond Zone Element.

\section{FINITE ELEMENT ANALYSIS}

The bond stress-slip response needs to be incorporated for the realistic analysis of the RC structures, and also to understand the micromechanical behavior at the interface. The efforts on the three dimensional behavior of the reinforced concrete systems using solid finite elements is limited. In this study a 3D finite element model with various bond mechanism have been described through the bond stress-slip response. The finite element modeling of the pull-out specimens has been carried out by using FEMAP and MASA, where the preprocessing (modeling) and post processing (results) have been performed using FEMAP, while the analysis in MASA [24].

The program MASA enables the non-linear 3D- finite element analysis of the reinforced concrete structures. The material model is based on the general micro-plane model for concrete. The reinforcement bar is modeled using uniaxial elasto-plastic stress-strain relationship with or without strain hardening or by $3 \mathrm{D}$ solid element. The concrete is discretized by the eight node (hexa) or four node (tetra) solid finite elements. Discretization of the reinforcement bars is performed by twonoded bar elements, truss elements or alternatively by beam elements. As a global solution strategy, the stiffness matrix can be formed in three ways (1) constant stiffness method (CSM), (2) tangent stiffness method (TSM) and (3) secant stiffness method (SSM). The analysis is incremental and therefore the total applied load has to be divided into a number of load or displacement increments. To prepare the input data as well as to analyze the results of the finite element analysis, commercial pre- and post-processing package FEMAP is used. This program generates nodes, nodal connectivity, boundary conditions, material data and loads which are required for the finite element code MASA. The link between FEMAP and MASA is realized through an input interface program which from FEMAP output data generates input data of the FE code. The interface program can be run directly from MASA main control panel. Moreover, to generate the post-processing output results from the numerical results of the FE code, an 
output interface program has be used. The post-processing output results are read and graphically interpreted by FEMAP.

\subsection{Micro-Plane Model for Concrete}

The three dimensional macroscopic modeling of concrete is characterized by a relationship between stress and strain components on various planes. These planes are imagined to represent the damage planes or weak planes in the microstructure, such as contact layers between the aggregates in concrete. The uni-axial stress-strain relations are used to calculate the micro-plane stresses and strains on each of these damage or weak planes. Finally, the integration over all the micro-planes results in the macroscopic stresses and strains over the entire three dimensional space as shown in Fig. 6.
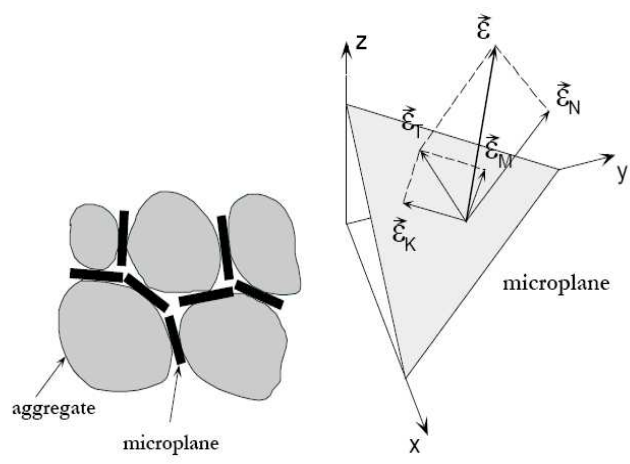

Fig6. Micro-plane Model

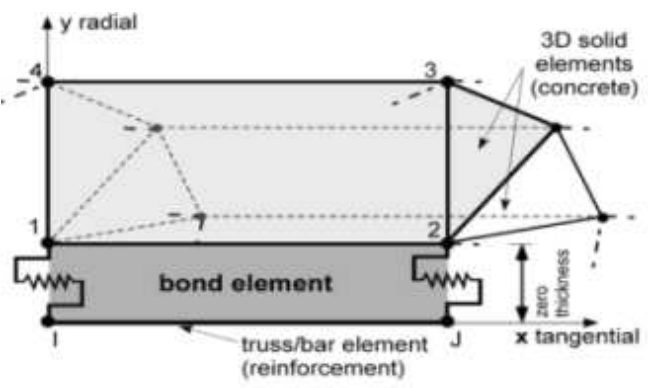

Fig7. Bond Element.

\subsection{Discrete Bond Model for 3D FEA}

The link between the reinforcement and the concrete may be modeled either by continuous or discrete connection. The application of the bond models by any one of these approaches is difficult in finite element modeling; due to several parameters affect the bond behavior. The discrete bond model as shown in Fig. 7 defines the bond strength and the stiffness as a function of the relative slip between the reinforcing steel and the concrete. The zero thickness spring elements connect the steel reinforcement bar i.e. truss or bar finite element, with the surrounding concrete elements i.e. solid finite element. The degree of freedom is considered only in the direction of reinforcing bar i.e. in the direction of slip, whereas, the connection with the concrete perpendicular to the bar is considered to be perfect. The tangential and radial stresses are generated when the ribbed bar is pulled out from a concrete block. It is assumed that the radial stresses are generated by the concrete finite elements. In finite element code MASA, discrete bond is defined based on the bond stress-slip response assumed.

\subsection{Modeling of Pull-Out Specimen}

The generic pull-out specimens (150mm x 150mm x $150 \mathrm{~mm}$ ) were modeled in FEMAP and discritized with solid elements of concrete and bar elements with discrete bond elements for reinforcement. The transverse reinforcement is modeled as $3 \mathrm{D}$ solid elements as shown in Fig. 8 with perfect bond.
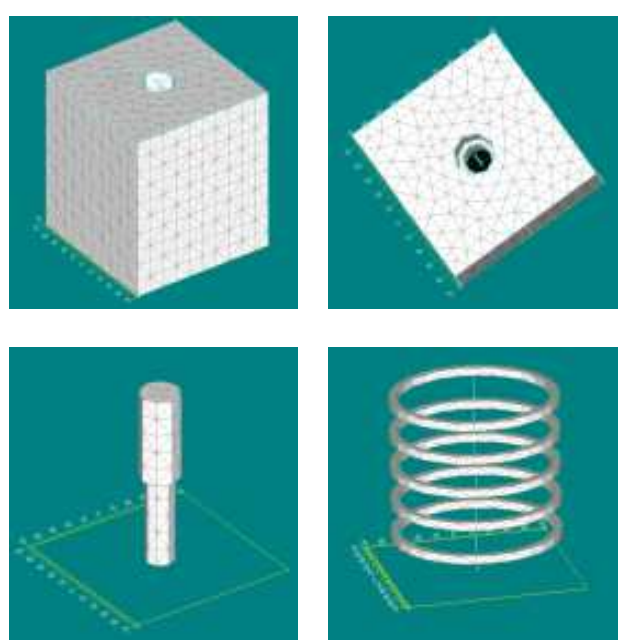

Fig8. Modeling of Concrete, Concrete around Bar and Transverse Reinforcement.

As the reinforcing bar and concrete interface is modeled as discrete element of zero thickness and concrete in the vicinity of the bar is subjected to higher stresses during loading than the surrounding concrete, the surrounding concrete and the concrete surrounding the bar are separately modeled and embedded finally. The concrete in the vicinity of the bar is modeled as cylindrical concrete. The effect of the plastic sleeve is modeled by assigning a lesser compressive strength in the cylindrical concrete. Appropriate boundary conditions are also defined. The controlled displacement was applied to get the post-peak response of the load-deflection curve.

\subsection{Material Properties}

The constitutive law of concrete was defined by the uniaxial compression and uniaxial tension stress-strain responses. The five basic parameters of concrete can define these curves: Young's modulus, Poisson's ratio, tensile strength, cylinder Compressive strength and fracture energy of concrete. The direct tensile strength of concrete was used in this analysis. 
The fracture energy of concrete for a given strength has been obtained from Table 2.1.4 of the CEB-FIP Model Code (25), which is given as the following equation,

$$
G_{F}=G_{F O}\left(f_{c m} / f_{c m o}\right)^{0.7}
$$

Where,

$f_{c m}=$ Mean compressive strength

$f_{\text {cmo }}=10 \mathrm{MPa}$

$G_{F O}=0.030 \mathrm{Nmm} / \mathrm{mm}^{2}$, base fracture energy for aggregate

size of $16 \mathrm{~mm}$

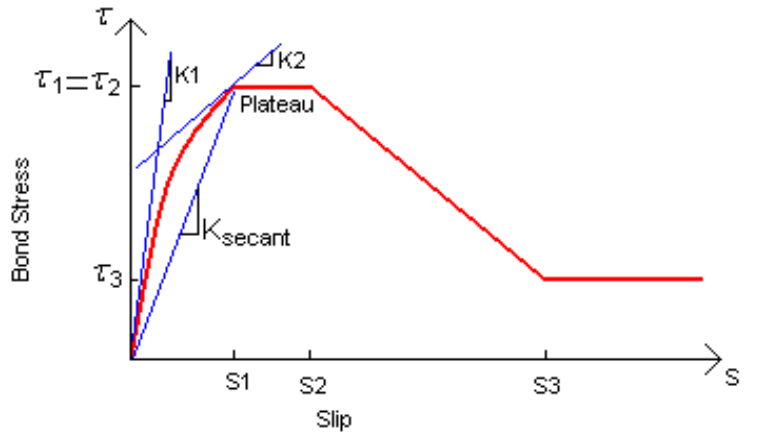

Fig9. Bond Properties of Concrete.

The bond properties were defined by the bond stress-slip response as shown in Fig. 9. The bond parameters were obtained from the experiments. The bond parameters are; ultimate strength, ultimate frictional bond strength, secant of bond response joining the origin and the peak stress, slip at the ultimate bond strength $\left(\mathrm{s}_{1}\right)$, slip where the ultimate bond strength begins to decrease $\left(\mathrm{s}_{2}\right)$, slip corresponding to the end of mechanical bond resistance $\left(\mathrm{s}_{3}\right)$, initial tangent to bond-slip response $\left(\mathrm{k}_{1}\right)$ and the tangent at the peak $\left(\mathrm{k}_{2}\right)$. These properties are given in Tables 1-3.

Table-1: Basic Material Properties of Concrete.

\begin{tabular}{|c|c|c|c|c|c|}
\hline $\begin{array}{l}\dot{0} \\
\dot{Z}\end{array}$ & 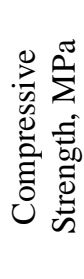 & 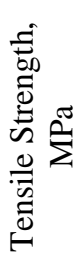 & 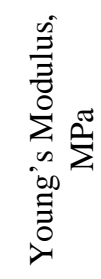 & 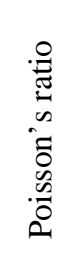 & 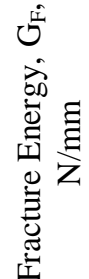 \\
\hline 1 & 25 & 1.80 & 25000 & 0.20 & 0.060 \\
\hline 2 & 40 & 2.20 & 31650 & 0.20 & 0.077 \\
\hline 3 & 65 & 3.80 & 40310 & 0.20 & 0.110 \\
\hline
\end{tabular}

\section{RESULTS AND DISCUSSION}

The bond strength of concrete using pull-out specimens was studied experimentally also. The finite element analysis of the pull-out specimens has been compared with the experimental observations. The results are matching well with the experimental values. The bond stress-slip responses obtained from the numerical investigations and the experimental studies are shown in Fig. 10. The pull out type of failure was observed in all the specimens with confinement reinforcement and splitting type of failure was encountered in the unconfined specimens. The bond stress at the initiation of the splitting of concrete was about 6.0 to $12.6 \mathrm{MPa}$ in concretes of 25,40 and $50 \mathrm{MPa}$ compressive strengths. After the peak load was reached, a sudden drop in the load has been observed. The descending branch shows that the bond stress due to frictional resistance is in the range of 0.6 to $1.3 \mathrm{MPa}$ for the unconfined concrete specimens. In the concrete confined with the transverse reinforcement the concrete splitting cracks were controlled by the confining steel reinforcement and the failure was due to pulling out of bars. The maximum bond stress ranges between 10.5 to $21.0 \mathrm{MPa}$ depending on the strength of surrounding concrete. For the concrete with lateral confinement the maximum bond stress was reached when the slip $\left(\mathrm{s}_{1}\right)$ was between $0.5 \mathrm{~mm}$ and $1.8 \mathrm{~mm}$. A horizontal plateau has been formed at the maximum bond stress, $\tau_{\max }$ at a slip between $0.8 \mathrm{~mm}-2.0 \mathrm{~mm}$. Thereafter, the bond resistance gets reduced to $\tau_{\mathrm{f}}$ (frictional bond resistance) at a slip $\left(\mathrm{s}_{3}\right)$ between $8 \mathrm{~mm}$ to $12 \mathrm{~mm}$. Then the bond resistance remains constant thereafter.

Table-2: Basic Material Properties of Steel.

\begin{tabular}{|c|c|c|c|c|}
\hline $\begin{array}{l}\dot{Z} \\
\dot{s}\end{array}$ & 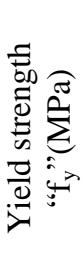 & 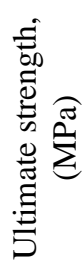 & 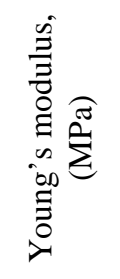 & 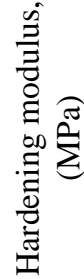 \\
\hline 1 & 250 & 360 & 200000 & 2000 \\
\hline 2 & 415 & 600 & 200000 & 2200 \\
\hline
\end{tabular}


Table-3: Bond Parameters of Concrete.

\begin{tabular}{|c|c|c|c|c|c|c|c|}
\hline $\begin{array}{l}\dot{0} \\
\dot{z} \\
\dot{s}\end{array}$ & 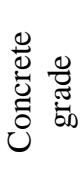 & 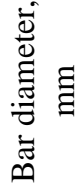 & 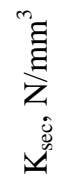 & $\frac{{ }^{m} \Xi}{\dot{Z}}$ & $\begin{array}{l}{ }^{m} \Xi \\
\tilde{z} \\
\dot{z} \\
\hat{z}\end{array}$ & $\frac{\sum^{\pi}}{\tilde{\sigma}^{-}}$ & $\stackrel{\tilde{\Sigma}}{\sigma}_{\sim}^{\pi}$ \\
\hline 1 & \multirow{3}{*}{ M25 } & 16 & 13.0 & 31.2 & 1.1 & 6.4 & 5.2 \\
\hline 2 & & 20 & 12.3 & 29.6 & 1.0 & 6.1 & 5.0 \\
\hline 3 & & 25 & 11.6 & 27.9 & 0.9 & 5.7 & 4.6 \\
\hline 4 & \multirow{3}{*}{ M40 } & 16 & 15.2 & 36.5 & 1.4 & 7.5 & 6.1 \\
\hline 5 & & 20 & 14.4 & 34.5 & 1.2 & 7.1 & 5.8 \\
\hline 6 & & 25 & 13.6 & 32.7 & 1.1 & 6.7 & 5.5 \\
\hline 7 & \multirow{3}{*}{ M65 } & 16 & 17.9 & 42.9 & 1.5 & 8.8 & 7.2 \\
\hline 8 & & 20 & 16.9 & 40.6 & 1.3 & 8.3 & 6.8 \\
\hline 9 & & 25 & 16.0 & 38.4 & 1.2 & 7.9 & 6.4 \\
\hline
\end{tabular}

\subsection{Influence of Strength of Concrete}

Three different concretes with compressive strengths of 25, 40 and $65 \mathrm{MPa}$ were considered. Using the $16 \mathrm{~mm}$ diameter bars in concrete of 25,40 and $65 \mathrm{MPa}$ strengths without lateral confinement for $150 \mathrm{~mm}$ embedment length, the stiffness of the ascending branch increases as the strength of the concrete increases. The maximum bond stress $\left(\tau_{\max }\right)$ reaches when the slip $\left(\mathrm{s}_{1}\right)$ ranges from $0.5 \mathrm{~mm}$ to $2.0 \mathrm{~mm}$. It has also been observed that as the concrete strength increases, the bond strength increases. The maximum bond stress occurs at a small slip, which agrees well with the previous reports. The slope of the descending branch increases with the decreasing concrete strength, which shows that the low strength concrete is more ductile than the high strength concrete. The frictional resistance $\left(\tau_{\mathrm{f}}\right)$ showed to increase with the increasing strength of concrete.

\subsection{Influence of Bar Diameter}

The influence of the reinforcing bar diameter has been observed on the maximum bond strength. The maximum bond strength decreases slightly with the increase in the bar diameter. For $16 \mathrm{~mm}$ bars the ascending branch of bond stressslip curve is steeper and the maximum bond strength $\left(\tau_{\max }\right)$ is reached at a relatively lower slip value. The maximum bond stress $\left(\tau_{\max }\right)$ using 20 and $25 \mathrm{~mm}$ diameter bars was attained at a slip value greater than that of $16 \mathrm{~mm}$ bar, which clearly shows that the slip at the peak load increases. The slope of the ascending branch of the bond stress-slip is relatively mild with $20 \mathrm{~mm}$ and $25 \mathrm{~mm}$ diameter bars. The variation of the reinforcing bar diameter does not have significant influence on the extent of the plateau $\left(s_{2}-s_{1}\right)$. The post peak response was found to be very similar for the entire range of bar diameters. The frictional bond resistance $\left(\tau_{\mathrm{f}}\right)$ with 16,20 and $25 \mathrm{~mm}$ diameter bars is not different within the range of the bar diameters adopted.

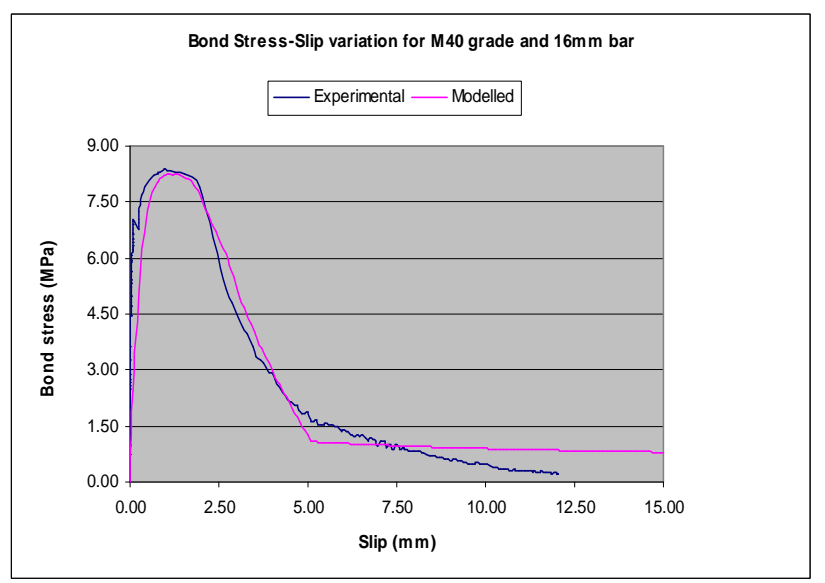

Fig10. Comparison of numerical results with experimental observations.

\subsection{Influence of Embedment Length}

The embedment lengths adopted in this study were $50 \mathrm{~mm}$, $75 \mathrm{~mm}$ and $150 \mathrm{~mm}$. The embedment lengths used were $50 \mathrm{~mm}$ and $75 \mathrm{~mm}$ plastic sleeves in the remaining portion, and for $150 \mathrm{~mm}$ embedment length the bar was fully embedded in concrete of size $150 \mathrm{~mm}$. The maximum bond stress $\left(\tau_{\max }\right)$ was relatively higher with smaller embedment length, which was achieved at a lower slip. There has not been a significant variation in the slope of the ascending branch as well as the maximum bond stress plateau. But the post peak response shows that for the concrete with $50 \mathrm{~mm}$ embedment length, the descending branch has been observed to be more ductile compared to the concrete with 75 and $150 \mathrm{~mm}$ embedment lengths. For $50 \mathrm{~mm}$ embedment length, the horizontal plateau of the slip $\left(s_{3}-s_{2}\right)$ is lesser than that of the one corresponding to 75 and $150 \mathrm{~mm}$ embedment lengths. Normally the frictional resistance $\left(\tau_{\mathrm{f}}\right)$ with $50 \mathrm{~mm}$ embedment length should have been lesser than that of $150 \mathrm{~mm}$ embedment length. But as per the analytical results the behavior is entirely different. It might have been due to crushing of the cylindrical concrete (plastic sleeve) which was providing additional resistance for the pulling out of reinforcement.

\subsection{Influence of Confinement due to Reinforcement}

The influence of confinement on the bond stress-slip behavior was studied to distinguish the type of failure. The splitting failure can be delayed or avoided altogether by providing the confining reinforcement. By providing the transverse reinforcement, the maximum bond stress was found to be increased. Usually, it is assumed that once pull-out failure is reached either by providing a large concrete cover or a sufficiently strong restraining (confining) reinforcement, $\tau_{\max }$ cannot be increased further. But it has been observed from the test results that the concrete confined with the spiral reinforcement performed better than the unconfined concrete. 


\subsection{Influence of Specimen Geometry}

Three different types of geometry designed with full embedment, embedment at the middle and embedment at the top were compared. The embedment lengths adopted were $5 \mathrm{~d}$ and $15 \mathrm{~d}$ with other parameters constant. For the specimens with small embedment length the bond strength has been observed to decrease with increase of the bar diameter. In the specimens with large embedment length, the maximum bond strength has been observed to be the same with the entire bar diameters. The descending branch of the bond stress-slip curve falls smoothly with smaller diameter bars as compared to the large diameter bars. The frictional resistance of all the bars was the same and is observed to be about $10 \%$ of the peak stress. It has been found that the initial bond stiffness appears to be constant with different bar diameters and with varying embedment length. The bond stress-slip curves with $16 \mathrm{~mm}$ bar diameter were found to be gradual with very long post-peak plateau. As the bar diameter increases, the length of the postpeak plateau decreases. The peak bond stresses are the same with different bar diameters. Similar observations have been noticed in the specimens with $15 \mathrm{~d}$ embedment length. However, the slip differences between the end and the starting point of the horizontal plateau are $8.2,4.5$ and $1.8 \mathrm{~mm}$ respectively with 16,20 and $25 \mathrm{~mm}$ diameter bars. The bond strength at the peak is about $8.0 \mathrm{MPa}$ with $5 \mathrm{~d}$ embedment length, whereas it is $7.3 \mathrm{MPa}$ with $15 \mathrm{~d}$ embedment. This shows that as the embedment length increases the bond strength decreases.

\section{CONCLUSIONS}

From the analytical study, the following conclusions can be drawn.

1. The bond stress-slip response of the bars embedded in confined concrete has a characteristic shape. After reaching $\tau_{\max }$, the bond resistance decreases up to the ultimate frictional bond resistance, $\tau_{3}$ at a slip, $s_{3}$, and remains constant thereafter.

2. The bond resistance drops rapidly after the occurrence of splitting at the peak load. This phenomenon has been observed in unconfined specimens, which marked as the reference for the confined specimens.

3. The embedment length showed strong effect on the bond strength. As the embedment length increases the bond strength decreases.

4. The bond stress-slip response of different geometry with the same embedment length have been found to be the same

5. The influence of the bar diameter on the local bond stressslip relationship was rather negligible in the selected range of diameter $\left(\mathrm{d}_{\mathrm{b}}=16 \mathrm{~mm} 20 \mathrm{~mm}\right.$ and $\left.25 \mathrm{~mm}\right)$. The variation could be greater the bar diameter lesser is the ultimate bond stress, $\tau_{\max }$.

6. The post-peak response has been found to be gradual and prolonged with small diameter bars. As the bar diameter increases, the post peak response becomes steep.

\section{REFERENCES}

[1] Rehm, G., (1961), "Uber die Grundlagen des Verbudzwischen Stahl und Beton," Heft 138, Deutscher Ausschuss fur Stahlbeton, Berlin.

[2] Tepfers, R., and Olsson, P.A., (1992), "Ring test for evaluation of bond properties of reinforcing bars," Conference on Bond in concrete-from Research to practice. 1-89-1-99.

[3] Mathey, R.G., and Watstein, D., (1961), "Investigation of bond in beam and pull out specimens with high yield strength deformed bars," ACI Journal, 57, N.50, 10711089.

[4] Hansen, R.J., and Liepins, A.A., (1962), "Behaviour of bond in dynamic loading," ACI Journal, 563-583.

[5] Goto, Y., (1971), "Cracks formed in concrete around deformed tension bars," ACI Journal, 68, N.26, 244 251.

[6] Soroushian, P., and Choi, K.B., (1989), "Local bond of deformed bars with different diameters in confined concrete," ACI Structural Journal, T. No.86-S24, V. 86, N. 2, 217-222.

[7] Harajli, M.H., Hamed, B.S., and Rteil, A.A., (2004), "Efficient and confinement of bond strength between steel bars and concrete," ACI Structural Journal, 101, N. 58, 595-603.

[8] Lutz, L.A., and Gergely, P., (1967), "Mechanics of Bond and Slip of deformed bars in Concrete," ACI Journal, 64, No.62, 711-721.

[9] Jiang, D.H., Shah, S.P., and Andonian, A.T., (1984), "Study of the transfer of tensile forces by bond," ACI Journal, 81, No.24, 251-258.

[10] Soroushian, P., Choi, K.B., Park, G.H., and Aslani, F., (1991), "Bond of Def. Bars to Concrete: Effects of Confinement and Strength of Concrete." ACI Mat. Jl, 88(03), 227-232.

[11] Somayaji, S. and Shah, S.P., (1981), "Bond stress versus slip relationship and cracking response of tension members," ACI Journal, 78, No. 3, 217-225.

[12] De Larrard, F., Schaller, D., and Fuchs, J., (1999), "Effect of bar diameter on the bond strength of passive reinforcement in high performance concrete," ACI Material Journal, 90, No. 4, 333-339.

[13] Darwin, D., Zuo, J., Tholen, M.L., and Idun, E.K., (2000), "Development length criteria for conventional and high relative rib area reinforcing bars," $A C I$ Structural Journal, 93, No. 3, 347-359.

[14] Eligehausen, R., Popov, E.R. and Bertero, V.V. (1983), "Local bond stress-slip relation of deformed bars under generalized excitations,"- R. No. UCB/EERC-83/23

[15] CEB-FIP Report, Bond of reinforcement in concrete: state of the art report. FIB Bulletin 10, 2000, August, Switzerland. 
[16] IS 2770 -Part 1: 1997 "Method of testing bond in reinforced concrete Part I - Pull out test," Bureau of Indian standards.

[17] TC9-RC 1983: RILEM Standard RC6

[18] TC9-RC 1973: RILEM Beam Specimen RC 5.

[19] IS 456: Indian Standard Code of Practice for Plain and Reinforced Concrete. BIS, New Delhi, 2000.

[20] ACI 318: Building Code Requirements for Structural Concrete and Commentary, 2005, American Concrete Institute 1995 Farmington Hills, Michigan.

[21] ACI 408.3-01: Splice and development length of high relative rib area reinforcing bars in tension and commentary (2007).

[22] EN 1992: Design of Concrete Structures-Part 1.1: General rules and rules for buildings. European Standards, 2003.

[23] BS 8110-1:1997 "Structural use of Concrete, Part 1: Code of Practice for Design and Construction" British Standards Institution, London, 1997.

[24] Ozbolt, J., Lettow, S., and Kozar, I., (2003), "Discrete bond element for $3 \mathrm{D}$ finite element analysis of reinforced concrete structures". 